- Equip staff with the knowledge, skills and confidence to support bereaved children

- Support achievement of national policy ambitions, including Ambition 6 'Each Community Is Prepared To Help'

- Provide focused training for early career teachers.

The paper also includes a critical discussion of the role of different stakeholders.

\section{P-8 YOUTH PLAYS - USING ART AND DRAMA WITH BEREAVED TEENAGERS WHO WOULDN'T OTHERWISE ENGAGE}

Tracie Slade. Isabel Hospice, Welwyn Garden City, UK

\subsection{6/bmjspcare-2018-hospiceabs.33}

Background The intention was to connect with young people who wouldn't engage with a therapeutic group using drama and art. All felt very isolated, different to their peers and alone in grief after bereavements and significant losses (Di Ciacco, 2008).

I recognised there could be benefit from a group experience. However, I found that they were too avoidant or emotionally fragile to engage with the usual psychotherapeutic group that we hold (Dowdney, 2000).

Aims (i) To connect this group by putting on two short plays that were about loss and bereavement; (ii) To build confidence and resilience by handing over control of the plays and give them creative freedom and choice; (iii) To engage with the wider community and their peers.

Method With the support of a local theatre director, we sourced some short youth plays that would facilitate talking and thinking about loss and bereavement by sharing the characters' experiences in the plays. This would help the young people by externalising their feelings and putting themselves into the shoes of the characters (Curtis, 1999).

The young people chose their roles e.g. to act, as stage manager, to make props or be sound technicians. This gave the young people a voice and purpose within the group. We managed to get local media students to join the group to evidence the process using video and photographs and help by giving confidence and self-worth.

Conclusion The group were anxious about meeting expectations and how they would share experiences with strangers. By sharing and participating together, giving them control and allowing choice, the group started to form bonds. The group took risks, made suggestions and felt accepted. Six out of six children reported it helpful being with others that had experienced similar issues, one didn't know. Five out of six children felt more confident after the youth plays.$$
\text { P-9 }
$$$$
\text { 'LOST VOICES' AN EVALUATION OF MARIE CURIE WEST }
$$ MIDLAND CHILDREN AND YOUNG PERSONS' SERVICES}

Ann Scanlon, Hannah Wilson, Suzanne McArthur, Nikki Reed. Marie Curie Hospice, West Midlands, Solihull, UK

\subsection{6/bmjspcare-2018-hospiceabs.34}

Background Since 2015 referrals to the children and young persons' counselling service at Marie Curie Hospice West Midlands have increased by $136 \%$. The complexities of the cases between 2017-2018 have also doubled, which we have found has been primarily due to an increase in mental health concerns with children.

At the British Association for Counselling and Psychotherapy (BACP) Young Persons' conference 2018 it was reported that $15 \%$ of young peoples' psychological disorders derive from unresolved grief. Current models of best practice suggest that we need to provide a service that supports the young person, their parents and the community in helping children work through their grief and life experiences in a way that is flexible and creative.

Aim The aim of the evaluation was to ascertain what the profile of children's counselling services within the hospice is and what role the children's bereavement service has in supporting children with mental health conditions work through their grief.

Methods We completed the evaluation by reviewing clinical documents and comparing them to policy.

Results We found that a common misconception was that the children's bereavement service offers time-limited, programmed counselling appointments for children to address their grief. We established that there was also a service gap for children with mental health conditions who are experiencing loss and grief. The current systems are not meeting their needs in a timely manner. Finally, there is an identified increasing need for children with complex needs to access specialist grief counselling.

Recommendations We recommended expanding the children's bereavement service by training volunteers and employing another part time counsellor. This will enable the team to deliver training in schools and work more closely with community services in supporting children during their grieving process.

\section{P-10 SIDE BY SIDE - A JOURNEY THROUGH GRIEF TOGETHER}

Jane Archdeacon, Katherine Birch, Justine Wilson. Compton Care, Wolverhampton, UK

10.1136/bmjspcare-2018-hospiceabs.35

Background NICE standards require that 'people closely affected by a death are communicated with in a sensitive way and are offered immediate and ongoing bereavement, emotional and spiritual support appropriate to their needs and preferences' (NICE, 2011). Consequently, significant attention is being paid to the nature and type of bereavement support and services offered within and across organisations and communities.

Bereavement is not, in itself, an illness and the majority of people affected will experience 'normal'/'uncomplicated' bereavement (Shear, Simon, Wall, et al., 2011; Mancini, Bonanno \& Sinan, 2014). Most of those who are bereaved (circa 60\%) deal with their grief with the support of family and friends and a further $30 \%$ may need additional support (e.g. peer support/volunteer led groups). Only 10\% are at risk of a more complicated grief reaction and may need referral to mental health professionals (op. cit.).

The Bereavement Care Service Standards (Bereavement Services Association \& Cruse Bereavement Care, 2013) include the need for providers to 'address the needs of the client group/community they serve in the most appropriate way' and 'to ensure that those delivering support... have the skills, knowledge, training, supervision and support relevant to their role'. 